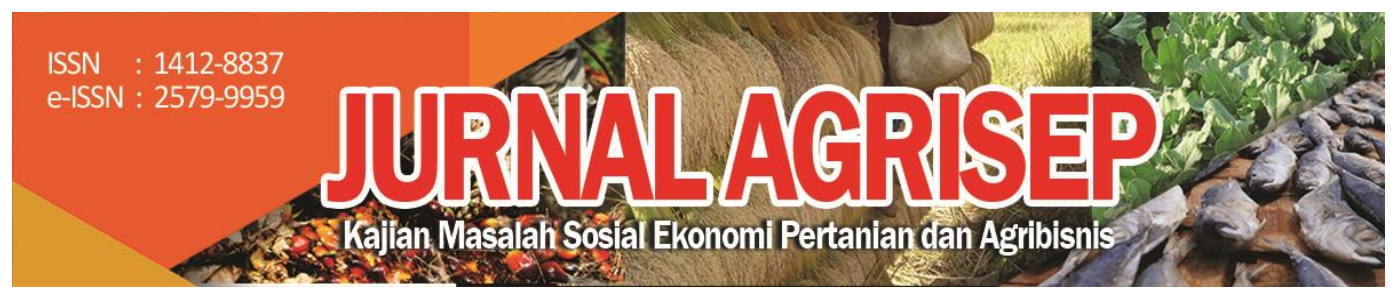

DOI: $10.31186 /$ jagrisep.20.1.95-102

\title{
ETNOGRAFI KOMUNIKASI KANURI LAOT MASYARAKAT NELAYAN KECAMATAN SAMATIGA KABUPATEN ACEH BARAT
}

\section{Communication Etnography Kanuri Laot of Fisherman Community, Samatiga Subdistrict West Aceh District}

\author{
Khori Suci Maifianti ${ }_{1 \text { ); Raidayani2) }}$ \\ 1)Program Studi Agribisnis Fakultas Pertanian Universitas Teuku Umar \\ 2) Program Studi Agribisnis Fakultas Pertanian Universitas Teuku Umar \\ Email: khorism@utu.ac.id
}

\begin{abstract}
This paper aims at analyzing the effect of Kanuri Laot in Samatiga, West Aceh, starting from the setting for preparation and the implementation of Kanuri Laot. The data were obtained through in-depth interviews with the implementing actors of Kanuri Laot accompanied by testing of interview data so that the data collected was tested. From the results of data testing, it was found that the preparatory setting was carried out indefinitely, it depended on the results of community deliberations. The implementation of the Kanuri Laot took place at Kuala Bubon beach with the implementation time being chosen on Sunday ofs every January.
\end{abstract}

Keyword: Kanuri Laot, Ritual communication, Communication Etnograph, Fisherman community

\section{ABSTRAK}

Penelitian ini bertujuan untuk mendeskripsikan setting pelaksanaan Kanuri Laot di Kecamatan Samatiga Kabupaten Aceh Barat, dimulai dari setting persiapan pelaksanaan, setting pelaksanaan Kanuri Laot. Deskripsi diperoleh melalui wawancanra mendalam terhadap pelaku pelaksanan Kanuri Laot disertai pengujian data hasil wawancara agar data yang terkumpul teruji. Dari hasil pengujian data ditemukan bahwa setting persiapan dilakukan dalam waktu yang tidak terbatas bergantung kepada hasil musyawarah warga. Pelaksanaan Kanuri Laot dilangsung di lokasi pantai Gampong Kuala Bubon dengan waktu pelaksanaan dipilih pada hari minggu setiap bulan januari. 
Keyword: Kanuri Laot, Komunikasi Ritual, Etnografi komunikasi, Masyarakat Nelayan

\section{PENDAHULUAN}

Etnografi komunikasi ialah penelitian yang menggunakan metode dengan tiga unit analisis yaitu situasi komunikasi, peristiwa komunikasi dan tindakan komunikasi (Irawan, 2018). Menurut Saville-Troike (2003) etnografi lahir karena adanya hubungan bahasa, komunikasi, dan kebudayaan secara bersama. Hal ini dapat disimpulkan bahwa komunikasi tidak dapat dipisahkan dari kehidupan manusia, selain itu komunikasi juga dapat membangun konsep diri, contohnya ialah komunikasi ritual.

Mulyana (2010) menyebutkan bahwa komunikasi ritual lazim dilaksanakan oleh suatu komunitas, baik berupa upacara yang melibatkan seluruh komunitas maupun acara yang bersifat personal atau keluarga yang dimulai dari lahiran, sunatan, ulang tahun, pertunangan, siraman, pernikahan atau kematian. Hal ini memunculkan perilaku simbolik yang terjadi setiap kali dilakukan komunikasi ritual. Contoh yang dapat dikemukaan adalah upacara ritual sekaten (Nurdiarti, 2017), ritual slametan di Surabaya (Handayani,2018), ruwatan di masyarakat Jawa (Yanti,2013), komunikasi ritual dalam tarian seblang Banyuwangi (Prihastuti \& Laturrakhmi,2017), ritual seblang oleh orang using (Saputra,2014), Masquerades di Afrika (Ajala,2011), tradisi hari raya enam di Kelurahan Pulau Kecamatan Bangkinang (Awali dan Yohana,2019), sedekah laut Desa Pulau Kelapa Kepulauan Seribu (Setiawati,2019), ritual tumpek wariga di Bali (Sudarsana, 2017), ritual tolak bala (Hasbullah dkk, 2017), bahkan di rumah sakitpun memiliki etnografi pelayanan media (Putri dan Sifatu, 2018).

Komunikasi ritual biasanya dilakukan secara kolektif dan erat kaitannya dengan komunikasi ekspresif (Nurdiarti,2017). Salah satu contoh komunikasi ritual ialah kanuri laot. Ritual kanuri laot ialah ritual yang terjadi pada komunitas masyarakat nelayan. Pada kegiatan ritual ini munculnya interaksi sosial, baik interaksi individu dengan individu, individu dengan masyarakat, dan individu dengan Allah SWT. Interaksi sosial berisikan harapan-harapan masyarakat yang tersalurkan dalam perilaku komunikasi.

Perilaku komunikasi yang sudah terbentuk dan berpola (Istiyanto dan wiwik, 2018) menjadi penyebab lahirnya kebiasaan yang menjadi ciri karakteristik yang khas yang kemudian disebut sebagai budaya. Oleh karena itu, kegiatan komunikasi dari anggota komunitas budaya tertentu menjadi representasi dari sikap, nilai-nilai dasar dan pandangan hidup dari budayanya. Di samping itu, penggunaannya dalam komunikasi juga akan memperkuat nilainilai dan sikap tersebut dalam eksistensinya di komunitas budaya tersebut.

Ritual Kanuri laot merupakan ritual rutin yang biasanya dilakukan oleh masyarakat nelayan. Kanuri laot merupakan rasa syukur yang dilakukan oleh masyarakat nelayan. Dalam kegiatan kanuri laot, semua nelayan seluruh Kecamatan Samatiga diundang dan ikut terlibat dalam ritual ini. Ritual ini 
dilakukan dengan swadaya masyarakat nelayan. Fungsi dari kanuri laot adalah sebagai rasa syukur ke Allah SWT yang telah memberikan rezeki ke masyarakat nelayan. Ketua atau penanggungjawab dari kegiatan kanuri laot adalah panglima laot. Penetapan waktu pelaksanaan kanuri laot berdasarkan hasil musyawarah panglima laot, aparat gampong dan masyarakat nelayan. Kanuri laot biasanya dilakukan setiap bulan Januari, dikarenakan pada bulan Januari adalah musim timur.

Masyarakat pesisir dalam tuturannya memiliki kekhasannya tersendiri yang membedakannya dengan masyarakat tutur lain. Kekhasan inilah yang menjadi daya pikat untuk diteliti. Dari uraian latar belakang tersebut, dapat ditemukan permasalahan penelitian yaitu analisis etnografi komunikasi kanuri laot pada masyarakat nelayan di Kecamatan Samatiga Kabupaten Aceh Barat. Penelitian ini bertujuan untuk menganalisis etnografi komunikasi kanuri laot pada masyarakat nelayan di Kecamatan Samatiga Kabupaten Aceh Barat.

\section{METODE PENELITIAN}

Metode penelitian yang dipakai dalam penelitian ini adalah metode etnografi komunikasi. Metode ini dipilih berdasarkan pertimbangan bahwa hubungan-hubungan dari kategori dan data dalam penelitian ini hanya akan dapat digambarkan dan dijelaskan dengan baik oleh metode ini. Hal ini sejalan dengan pendapat Kuswarno (2011) bahwa tujuan studi etnografi komunikasi adalah untuk menggambarkan, menganalisis, dan menjelaskan perilaku komunikasi dari suatu kelompok sosial. Objek yang diteliti dalam penelitian ini adalah ritual kanuri laot yang biasanya tiap tahun diadakan oleh masyarakat nelayan. Untuk memperoleh informasi peneliti melakukan wawancara mendalam dan selanjutnya dilakukan triangulasi. Pengambilan informan sebanyak 22 orang yaitu keuchik, panglima laot, tauke bangku, panglima lhok, nelayan sebanyak 8 orang, pemuda-pemudi 5 orang, anak-anak 2 orang, dan perempuan nelayan 3 orang. Dengan key informan keuchik, panglima laot, dan panglima lhok.

Penelitian melakukan analisis data mulai dari pengumpulan data sampai menghasilkan laporan penelitian. Tahap-tahap analisis data dalam penelitian ini adalah reduksi data, penyajian data, pengambilan keputusan dan verifikasi (Miles dan Huberman, 2007). Selain itu, verifikasi data juga dilakukan dengan metode focus group dissucion (FGD) yang mana yang hadir pada acara itu adalah keuchik, panglima laot, panglima lhok, nelayan, dan aparat desa lainnya.

\section{HASIL DAN PEMBAHASAN}

Aktivitas kehidupan sehari-hari masyarakat nelayan pada keadaan sosial yang didalamnya terbentuk dari saling berkaitannya antara aspek sosial kultural dan struktural sosial masyarakat. Rasa saling tolong menolong sangat terlihat di 
antara masyarakat ini. Dalam kondisi dinamika kehidupan yang menunjukkan sebuah ciri kondisi spesifik pedesaan. Dalam pelaksanaan Kanuri laot sangat terlihat bentuk kerjasama di masyarakat nelayan dan juga sangat terlihat besarnya rasa syukur masyarakat nelayan kepada Allah SWT. Selain itu masyarakat nelayan juga berdo'a agar Allah SWT selalu memberikan rezeki.

Ritual yang dilakukan turun temurun ini memunculkan pola-pola komunikasi yang awalnya dimunculkan oleh Hymes pada tahun 1972. Pada tahun 2004, Hymes menganalisis bahwa sebuah peristiwa komunikasi terjadi dalam situasi komunikasi pada kegiatan ritual budaya, sehingga seorang peneliti harus memahami komponen yang membangun tuturan yaitu setting, participants, end, act sequence, key, instrumentalis, norm on interaction dan genre, yang sering disingkat dengan SPEAKING (Hymes,2004). Analisis komponenkomponen tersebut diharapkan dapat menelaah ritual kanuri laot sebagai peristiwa komunikasi.

Komponen pertama yang dianalisis ialah setting, dalam hal ini yang dilihat ialah waktu pelaksanaan ritual (Rifa'i, 2017). Selain waktu, hal lain yang dapat diamati ialah tata letak, dekorasi lapangan yang akan digunakan dalam ritual, perlengkapan ritual, dan luasnya ruangan ritual. Waktu, tempat, dan ruangan yang dilakukan oleh pelaku budaya yang dalam hal ini adalah masyarakat nelayan sangat menentukan peristiwa komunikasi ritual.

\section{Setting persiapan pelaksanaan kanuri Laot}

Setting meliputi waktu yang tepat digunakan untuk mempersiapkan ritual kanuri laot. ini adalah tak terbatas. Tergantung dari hasil musyawarah anggota kelompok hanya saja harus dalam musim timur. Musim timur merupakan musim terbaik untuk melaksanakan kanuri laot karena sering besarnya gelombang dilaut dan sedikitnya ikan membuat nelayan jarang ke laut untuk menangkap ikan. Sedangkan untuk harinya biasanya dipilih hari minggu agar semua anggota bisa menghadiri ritual kanuri laot, terutama untuk pemuda dan anak-anak. Namun di tahun 2020 ini, hasil musyawarah pelaksanaan kanuri laot jatuh pada hari selasa. Pada saat pelaksanaan kanuri laot, nelayan tidak dizinkan untuk berangkat ke laut. Lokasi tahap persiapan kanuri laot masyarakat nelayan dilakukan di balai desa.

\section{Setting pelaksanaan kanuri Laot}

Setting tempat pelaksanaan kanuri laot terjadi di lapangan bola Kuala Bubon yang letaknya dipinggir pantai. Terlihat beberapa kursi, tiga tenda yang sudah disediakan oleh panitia. Malam sebelum pelaksanaan kanuri laot setelah sholat insya berjamaah diadakan mengaji/tadarus sampai khatam Alqur'an. Pagi pukul 08.00 wib masyarakat sudah mulai berkumpul untuk memulai memasak, diharapkan pukul 12.00 wib masyarakat dan tamu undangan sudah bisa menikmati kuah beulangong (kuah daging khas aceh). 
Partisipan yang melaksanakan ritual kanuri laot merupakan seluruh masyarakat nelayan, semua geuchik yang ada nelayannya, Teungku Imuem, Panglima laot, Panglima lhok, Pemuda dan anak-anak, ustad, Camat atau pihak kecamatan, dinas perikanan dan kelautan, koramil, kapolsek yang paling penting adalah anak-anak yatim. Panglima laot wajib mengundang Teungku Imuem untuk mengaji dan berdo'a. Geuchik yang merupakan sesosok pemimpin formal untuk desa malah tidak diwajibkan. Anak-anak yang hadir disini merupakan anak-anak masyarakat nelayan dan anak yatim piatu.

Ends menganalisis maksud dan tujuan dari kegiatan ritual (Maifianti,2014). Ada dua peristiwa yang dimati dan dianalisis dari kanuri laot yaitu peristiwa yang menjadi sudut pandang budaya dan peristiwa yang menjadi tujuan peserta secara individu. Maka tujuan dari ritual kanuri laot adalah mensyukuri nikmat dan rezeki yang telah Allah SWT berikan, dan berdo'a agar dimudahkan dalam menangkap ikan dan diberikan rezeki lebih baik lagi. Tujuan dari peserta secara indivu dapat dianlisis sebagai kerjasama masyarakat nelayan.

Dijelaskan dalam act sequence bahwa bentuk ujaran berkenaan dengan kata-kata yang digunakan, bagaimana penggunaannya, dan hubungan antara apa yang dikatakan dengan apa yang menjadi topik ujaran. Dalam sambutan acara ritual, panglima laot menyampaikan petuah yang sifatnya berupa harapanharapan terhadap usaha melaut ke depannya, sedangkan kata-kata halus dan do'a digunakan pada saat tadarus, ceramah, dan berdo'a kepada Allah SWT.

Latar belakang keys yang menjadi perhatian khusus adalah pada intonasi (nada), cara, dan semangat dari suatu pesan yang disampaikan. Dari hasil pengamatan, pesan disampaikan secara santai dengan nada sopan, sehingga tidak terkesan adanya pemaksaan, dan isi pesan merupakan perulangan dari ritual di tahun-tahun sebelumnya. Ritual kanuri laot yang sangat ditunggutunggu, sehingga ritual ini bersifat santai dan tidak ada pemaksaan. Pada saat arahan Panglima laot cara penyampaianya lebih ke penyampaian pesan satu arah, sedangkan untuk yasinan, berdo'a dan makan bersama lebih ke dua arah.

Sarana tutur atau instrumentalities dalam ritual kanuri laot difokuskan pada mengamati jalur bahasa yang digunakan selama pelaksanaan ritual, baik berupa tuturan (lisan) maupun tulisan. Komunikasi satu arah merupakan jalur yang dipakai dalam ritual kanuri laot, dikarekan kuatnya rasa kepemimpinan keuchik dan panglima laot sehingga masyarakat nelayan sangat mengindahkan perintah-perintah dari pimpinan mereka. Keuchik dan Panglima Laot sangat mengharapkan masyarakat nelayan mengikuti semua hukum-hukum adat laot yang telah ditentukan dan disepakati bersama sejak dahulu. selain komunikasi satu arah juga dilakukan komunikasi dua arah, komunikasi ini terjadi pada momen makan bersama. Hal ini terjadi karena pimpinan dan masyarakat nelayan setara dimata Allah SWT. Dalam pelaksanaan kanuri laot, mereka menggunakan bahasa ibu yaitu bahasa aceh. 
Norm on Interaction pada ritual kanuri laot yaitu norma atau aturan interaksi yang terjadi pada saat pelaksanaan kanuri laot. Pelaksanaan ritual secara kelompok ini tidak ada norma dan aturan tertentu yang harus dipatuhi. Hanya norma atau aturan yang harus diam pada saat tadarus dan berdo'a. Aturan harus diam ini bukan saja terjadi pada saat ritual saja tetapi setiap ada tadarus dan berdo'a masyarakat Aceh diwajidkan untuk diam, mendengarkan bahkan diharapkan untuk menjawab Aminn. Dalam pelaksanaan ritual, perwujudan rasa syukur diwujudkan dalam kegiatan tadarus, yaitu mengkhatamkan Alqur'an dalam waktu satu malam, berdo'a yang dipimpin oleh orang yang dituakan dari segi agama atau Teungku Imuem dan santunan anak-anak yatim. Adapun rasa kerjasama dapat ditemukan pada kegiatan makan bersama yang menjadi norma di dalam interaksi yang ditemukan dalam ritual tersebut. Selain itu, sesudah kanuri laot ada tiga hari pantangan untuk nelayan melaut. Bagi yang tidak mengikuti pantangan maka akan ada sanksi sosial.

Ganre yang menjadi fokus amatan dalam penelitian ini adalah pada jenis dan bentuk penyampaian pesan. misalnya seperti narasi, puisi, do'a, dan hadih maja (pepatah). Komunikasi yang berlangsung pada ritual kanuri laot memang bersifat lisan, terkadang isyarat ataupun ungkapan non verbal terlibat di dalamnya. Percakapan yang terjadi ataupun ungkapan non verbal terlibat di dalamnya. Percakapan yang terjadi juga biasanya diselilingi hal-hal yang bersifat canda tawa. Dengan meninjau dialog yang diutarakan oleh panglima laot, penulis mengasumsikan bahwa tipe peristiwa atau genre pada ritual kanuri laot secara masyarakat nelayan adalah peristiwa interaksi antara anggota masyarakat nelayan dengan anggota masyarakat nelayan itu sendiri dan antara masyarakat nelayan dengan Allah SWT.

\section{SIMPULAN DAN SARAN}

\section{Simpulan}

Penelitian ini dapat disimpulkan bahwa setting tempat pelaksanaan kanuri laot terjadi di lapangan bola Kuala Bubon yang letaknya dipinggir pantai. Partisipan yang melaksanakan ritual kanuri laot merupakan seluruh masyarakat nelayan, semua geuchik yang ada nelayannya, Teungku Imuem, Panglima laot, Panglima lhok, Pemuda dan anak-anak, ustad, Camat atau pihak kecamatan, dinas perikanan dan kelautan, koramil, kapolsek yang paling penting adalah anak-anak yatim. Ends ritual kanuri laot tersebut adalah sebagai rasa syukur dan kepada Allah SWT untuk dipermudah dalam menangkap ikan dilaut dan sebagai rasa kerjasama nelayan. Act sequence Kata-kata yang digunakan oleh panglima laot menggunakan bahasa aceh dan lebih bersifat harapan kepada nelayan, sedangkan kata-kata halus dan do'a digunakan pada saat tadarus dan berdo'a memohon kepada Allah SWT. Keys, bersifat santai dan tidak ada pemaksaan. Instrumentalities dalam ritual ini adalah adanya komunikasi satu 
arah yang dilakukan dengan niat agar masyarakat nelayan mengikuti semua hukum-hukum adat laot yang telah ditentukan dan komunikasi berdialog pada saat makan bersama. Norm on Interaction pelaksanaan ritual secara kelompok ini tidak ada norma dan aturan tertentu yang harus dipatuhi. Hanya norma atau aturan yang harus diam pada saat tadarus dan berdo'a, dan pandangan tiga hari tidak menangkap ikan dimulai sejak setelah kanuri laot. Genre, penulis mengasumsikan bahwa tipe peristiwa atau genre pada ritual kanuri laot secara masyarakat nelayan adalah peristiwa interaksi antara anggota masyarakat nelayan dengan anggota masyarakat nelayan itu sendiri dan antara masyarakat nelayan dengan Allah SWT.

\section{Saran}

Saran dari penelitian ini yaitu diharapkan kepada panglima laot untuk dapat mempertahankan dan melaksanakan ritual kanuri laot ini setiap tahunnya agar terjalin silahturahmi nelayan sehingga bisa memupuk rasa kerjasama dan kekompakan antara nelayan, panglima laot, dan masyarakat.

\section{UCAPAN TERIMAKASIH}

Rasa terima kasih penulis sampaikan kepada RISTEK-BRIN atas hibah penelitian dosen pemula (PDP), Program Studi Agribisnis Fakultas Pertanian Universitas Teuku Umar, Keuchik dan aparat gampong Kuala Bubon, Panglima Laot dan masyarakat nelayan.

\section{DAFTAR PUSTAKA}

Awali, Gusmiarti, Nova Yohana. 2019. Etnografi Komunikasi Tradisi Hari Raya Enam Di Kelurahan Pulau Kecamatan Bangkinang. Jom Fisip, 6(1): 1-13. Ajala V O. 2011. African Natural/Cultural Communication Media: A Survey of Meanings and Usage at Tradisional Ceremonies. J Communication. 2(1): $1-12$.

Handayani, Sri. 2018. Agriculture and Ritual: Pola komunikasi ritual slametan musim tanam padi di ngemplak, sambikerep, surabaya. Jurnal Ilmu Komunikasi (J-IKA) V(1): 40-50.

Hasbullah, Toyo, dan Awang Azman Awang Pawi. 2017. Ritual Tolak Bala Pada Masyarakat Melayu (Kajian Pada Masyarakat Petalangan Kecamatan Pangkalan Kuras Kabuapaten Pelalawan). Jurnal Ushuluddin 25(1): 83100.

Hymes D. 2004. Ethnography Linguistic, Narrative Inequality Toward an Understanding of Voice. London (GB): This edition published in the Taylor \& Francis e-Library. 
Irawan, Dede. 2018. Studi Etnografi Komunikasi pada Organisasi Persatuan Islam. Communicatus: Jurnal Ilmu Komunikasi, Vol. 2 Nomor 1 2018:61-78. Istiyanto S. Bekti, Wiwik Novianti. 2018. Etnografi Komunikasi Komunitas yang Kehilangan Identitas Sosial dan Budaya di Kabupaten Cilacap. Jurnal Kajian Komunikasi, Vol. 6, No. 1, Juni 2018: 64-77.

Kuswarno E. 2011. Etnografi Komunikasi Suatu Pengantar. Bandung (ID): Widya Padjajaran.

Maifianti, Khori Suci, S. Sarwoprasodjo, dan D.Susanto. 2014. Komunikasi Ritual Kanuri Blang Sebagai Bentuk Kebersamaan Masyarakat Tani Kecamatan Samatiga Kabupaten Aceh Barat Provinsi Aceh. Jurnal Komunikasi Pembangunan, 12(2): 1 -12.

Miles M B, dan Huberman A. M. Analisis Data Kualitatif. Tjetjep Rohendi Rohidi, penerjemah. Jakarta (ID): Universitas Indonesia.

Mulyana D. 2010. Ilmu Komunikasi Suatu Pengantar. Bandung(ID): Rosda Karya.

Nurdiarti Rosalia Prismarini. 2017. Representasi Pangan Dalam Komunikasi

Ritual (kajian komunikasi ritual dalam perayaan sekaten di yogyakarta 2015-2016). Jurnal CHANNEL. 5(1):120-130.

Prihastuti Dinar, Yun Fitrahyati Laturrakhmi. 2017. Sebuah tudi Tentang Komunikasi Ritual Dalam Tarian Seblang Banyuwangi. Jurnal Studi Budaya Nusantara, 1(2): 72-79.

Putri, Annisa Azzahra Eka, Wa Ode Sifaru. 2018. Etnografi Pelayanan Medis Pada Pasien Rawat Inap Rumah Sakit Umum Daerah Di Kabupaten Muna. Kabanti: Jurnal Sosial dan Budaya, Vol 2, No. 2 Desember 2018.

Rifa'i, M. 2017. Etnografi Komunikasi Ritual Tingkeban Neloni dan Mitoni. Jurnal of Communication, 2(1), Juni 2017.

Saputra H SP. 2014. Wasiat Leluhur: Respon Orang Using terhadap Sakralitas dan Fungsi Sosial Ritual Seblang. Jurnal Makara Hubs-Asis. 18(1):51-65. Doi: 10.7454/mmsh.v18i1.3461.

Saville-troike. 2003. The Ethnography of communication: an introduction. Third Edition. Oxford (GB): Published Blackwel Publishing Ltd.

Setiawati, Rahmi. 2019. Makna Komunikasi Ritual "Sedekah Laut" Sebagai Pelestarian Nilai-Nilai Budaya Maritim Masyarakat Desa Pulau Kelapa Kepulauan Seribu. Prosiding Teknologi Terapan Inovasi dan Rekayasa (SNT2IR), 2(1): 436-446.

Sudarsana, I Ketut. 2017. Konsep Pelestarian Lingkungan Dalam Upacara Tumpek Wariga Sebagai Media Pendidikan Bagi Masyarakat Hindu Bali. Religious: Jurnal Studi Agama-Agama dan Lintas Budaya, 2, 1, September 2017: 1-7.

Yanti, Fitri. 2013. Pola Komunikasi Islam Terhadap Tradisi Heterodoks (Studi kasus tradisi ruwatan). Jurnal Analisis, Vol. XIII, Nomor. 1 Juni 2013: 201-218. 